\title{
An Experimental Study on Heat Transfer and Pressure Drop of CuO-Water Nanofluid
}

\author{
Bayram Sahin, ${ }^{1,2}$ Eyuphan Manay, ${ }^{2}$ and Eda Feyza Akyurek ${ }^{3}$ \\ ${ }^{1}$ Department of Mechanical Engineering, Faculty of Engineering, University of Ataturk, 25240 Erzurum, Turkey \\ ${ }^{2}$ Department of Mechanical Engineering, Faculty of Engineering \& Architecture, Technical University of Erzurum, \\ 25040 Erzurum, Turkey \\ ${ }^{3}$ Department of Mechanical Engineering, Faculty of Engineering, University of Gümüşhane, 29100 Gümüşhane, Turkey
}

Correspondence should be addressed to Eyuphan Manay; emanay@erzurum.edu.tr

Received 29 May 2015; Revised 28 August 2015; Accepted 6 September 2015

Academic Editor: Muhammet S. Toprak

Copyright (C) 2015 Bayram Sahin et al. This is an open access article distributed under the Creative Commons Attribution License, which permits unrestricted use, distribution, and reproduction in any medium, provided the original work is properly cited.

Heat transfer and pressure drop characteristics of water based $\mathrm{CuO}$ nanofluid inside a horizontal tube were investigated experimentally. The upper limitation of the particle volume fraction with respect to heat transfer performance was also found. $\mathrm{CuO}$-water nanofluids with volume fractions of $0.5 \%, 1 \%, 2 \%$, and $4 \%$ were prepared by dispersing the CuO nanoparticles with an average diameter of $33 \mathrm{~nm}$ into deionised water. Experiments were carried out under the steady-state, constant heat flux, and turbulent flow regime conditions. The variations of the average Nusselt number and the friction factor with the Reynolds number were presented. For all given particle volume concentrations, heat transfer enhancements were calculated. It was concluded that the particle volume concentrations higher than $1 \%$ vol. were not appropriate with respect to the heat transfer performance of the CuOwater nanofluid. No heat transfer enhancement was observed at $\mathrm{Re}=4.000$. The highest heat transfer enhancement was achieved at $\operatorname{Re}=16.000$ and $\phi=0.005$.

\section{Introduction}

The new heat transfer fluids obtained by the addition of the nanoscaled solid particles (copper, silver, aluminium, etc.) into the traditional heat transfer fluid are named "nanofluid" $[1,2]$. Nanofluids are thought by researchers to be appropriate for practical applications, as they cause very little increase in the pressure drop with regard to base liquid. Once the nanosized solid particles $(16-60 \mathrm{~nm})$ are perfectly suspended into the base fluid, the obtained fluid behaves as a single phase fluid rather than a solid-liquid mixture [3]. Researches related to the enhancement of convection heat transfer by the addition of the metal solid particles into the base fluid have been proceeding for the last two decades [4]. In the last studies that were conducted by the nanofluids named liquid-solid suspension in the beginning, it has been seen that the nanoscaled particles enhance the heat transfer and convection characteristics [5]. The heat transfer characteristics of the fluid used in the practical applications undertake the key role. As the classical fluids such as ethylene glycol, water, and oil limit the heat transfer capacity, alternative solutions should be developed $[6,7]$. In order to enhance the heat transfer capacity, the metal solid particle addition into the classical fluids with limited thermal conductivity is one of the major efforts [8]. Before the development of nanotechnology, experiments have resulted in failure, as the particles in millimeter or micrometer dimensions subsided in the base fluid and caused more increase in pressure drop than that of the base fluid $[9,10]$.

Noticeable efforts have been spent on the use of the nanoscaled particles such as diamond, $\mathrm{Au}, \mathrm{Cu}, \mathrm{Al}_{2} \mathrm{O}_{3}$, and $\mathrm{TiO}_{2}$ in the literature. The $\mathrm{Cu}$-water nanofluid was used in a circular horizontal tube by Xuan and Li [11]. The addition of the nanosized $\mathrm{Cu}$ particles into the water provided higher heat transfer. Another study of $\mathrm{Cu}$-water nanofluid was conducted by Chein and Huang [12]. The use of the nanofluid in a microchannel heat sink instead of using coolants improved the heat transfer and caused no extra pressure 
drop. Ma et al. [13] investigated the thermal performance of diamond-water nanofluids in heat pipes with oscillations. The combined effect of the oscillation motion and the enhanced thermophysical properties of the fluid increased the thermal performance and thus a cooling system model with higher thermal performance could be obtained. Tsai et al. [14] used $\mathrm{Au}$ nanoparticles in the heat pipes in order to create a water based nanofluid. It was seen that higher heat transfer rates were obtained by the use of the Au element in heat pipe systems. Au-water nanofluid was used in a disk shaped miniature heat pipe by Chien et al. [15]. The addition of the nanoscaled particles into the base fluid decreased the thermal resistance between the fluid flowing and the channel walls [15-17].

$\mathrm{CuO}$ compound is one of the most common types of nanoparticles used in heat transfer enhancement studies in the literature (Table 1). The convection heat transfer performance of water based $\mathrm{CuO}$ nanofluid was studied by Asirvatham et al. [18] in a copper pipe under the laminar flow conditions at lower particle concentrations and at different inlet temperatures. $8 \%$ heat transfer enhancement was obtained by using copper oxide-water nanofluid. The possible reasons for this increase in convection heat transfer are thought to be the enhanced thermophysical properties of the fluid and the acceleration of the energy exchange due to the ultrafine particles. Water based $\mathrm{CuO}$ nanofluid with 0.1 and $0.2 \%$ vol. was used in a thin channelled copper water block by Selvakumar and Suresh [19] under turbulent flow regime. A remarkable reduction in the interface temperature was achieved. The increase in the pressure drop was not at a significant level relative to the increase of the heat transfer coefficient. The dilute $\mathrm{CuO}$-water nanofluid in a circular tube was studied by Fotukian and Esfahany [8]. Nearly 25\% enhancement of the heat transfer coefficient was obtained when compared to pure water. By increasing the Reynolds number, the ratio of the coefficient of nanofluid to that of pure water decreased. Oil based $\mathrm{CuO}$ nanofluids were investigated under laminar flow conditions by Saeedinia et al. [20], Pooyan Razi et al. [21], and Hashemi and AkhavanBehabadi [22]. The presence of $\mathrm{CuO}$ particles in the oil base liquid increased the heat transfer much more than base oil $[20,21]$. The insertion of helical coiled wire increased both the heat transfer and the pressure drop more than that of the smooth tube. The coiled wire insertions enhanced the heat transfer characteristics of the nanofluids [22].

In the literature, there are many studies that report on the heat transfer performance of $\mathrm{CuO}$-water nanofluids. The enhancement on the heat transfer is believed to be a result of increase in thermal conductivity. It is a fact that the thermal conductivity increases as nanoparticle concentration increases. But, this does not mean that an increase in the thermal conductivity enhances continuously heat transfer by increasing particle volume fraction. After a value of particle volume concentration of nanofluids, increasing volume concentration decreases the rate of heat transfer because of the intensifying viscous sublayer caused by an increase in viscosity. The limitations of the $\mathrm{CuO}$ nanoparticle volume fraction with respect to heat transfer performance have not been studied so far clearly. In this study, particle volume fractions ranging from 0.5 vol.\% to 4 vol.\% were studied in order to determine the upper limitations of the particle volume fraction on the heat transfer performance. The combined effect of both the heat transfer and the pumping power was taken into consideration by examining the overall heat transfer enhancement of the $\mathrm{CuO}$-water nanofluid. The variations of the local Nusselt number were also presented to investigate the heat transfer behavior of the nanofluid along the test pipe.

\section{Experimental Set-Up and Procedure}

2.1. Preparation of Nanofluids. The term of nanofluid cannot be thought to be a simple solid-liquid mixture. Beyond being a simple mixture, the nanofluids prepared must have long durations with no sedimentation and must be agglomeratefree. Thus, the preparation of the nanofluids is the key issue requiring sensitivity and attention.

The nanofluids are prepared by the dispersion of the nanosized metal particles into traditional fluids such as oil, ethylene glycol, and water [23]. Two different methods are applied to prepare the nanofluids: a single step method and a two-step method. The main idea behind the method known as the single step method is to manufacture the nanoparticles in the base fluid. However, the distinction of the nanoparticles from the fluid in order to obtain dry nanoparticles is extremely difficult. In the two-step method, the nanoparticles obtained through different manufacturing methods are dispersed into the base fluid and thus the nanofluid is obtained [24]. In this study, the nanofluids have been prepared with two-step method by using $\mathrm{CuO}$ nanoparticles supplied from Sigma Aldrich Corporation with an average diameter of $33 \mathrm{~nm}$.

On the other hand, it is well known that thermophysical properties of a nanofluid depend on the particle type, size, shape, base fluid, and so forth. Deionized and distilled water are the most frequently used ones of water based nanofluids [25]. But deionized water can damage aluminium materials. Thus, distilled water has been used for both the smooth pipe experiments and the preparation of the nanofluids.

In literature survey, it is seen that there is a conflict on the effect of the surfactants on thermal conductivity enhancement. Some researchers [26-28] have found that surfactants increase the thermal conductivity of nanofluids, while some others [29-32] have concluded opposite behavior. In order to observe the effects of the surfactants on the stabilization of nanofluids, cetyltrimethylammonium bromide (CTAB) and sodium dodecylbenzenesulfonate (SDBS) have been used as the dispersant in different volume fractions. The images of the water based $\mathrm{CuO}$ nanofluids prepared without any dispersant (Tube-1) with CTAB (Tube-2, Tube-3, and Tube-4; with $0.5 \%$, $1 \%$, and $1.5 \%$ dispersant, resp.) and with SDBS (Tube- 5 , Tube6 , and Tube- 7 ; with $0.5 \%, 1 \%$, and $1.5 \%$ dispersant, resp.) are presented in Figure 1. The visual observations under a fluorescent light source have been conducted by the samples kept on hold for 28 days. Because no significant difference has been observed with respect to the stability among the samples, the nanofluids have been prepared without using any dispersant for the purpose of avoiding unknown effect 
TABLE 1: Experimental studies of water based $\mathrm{CuO}$ nanofluids.

\begin{tabular}{|c|c|c|c|c|c|c|}
\hline Author & $\begin{array}{l}\text { Base } \\
\text { fluid }\end{array}$ & $\begin{array}{l}\text { Particle } \\
\text { material }\end{array}$ & $\begin{array}{l}\text { Volume } \\
\text { fraction } \\
\text { (vol.\%) }\end{array}$ & $\begin{array}{l}\text { Channel geometry } \\
\text { and dimension }\end{array}$ & $\begin{array}{l}\text { Flow } \\
\text { regime }\end{array}$ & Results and remarks \\
\hline
\end{tabular}

Asirvatham et Water $\mathrm{CuO} \quad 0.003$ al. [18]

Copper tube

$L: 1.5 \mathrm{~m}$; ID: $8 \mathrm{~mm}$

Laminar

(i) The nanoparticles increased the heat transfer up to $8 \%$

(ii) At the entrance region, the heat transfer enhancement increased and decreased with the increasing axial distance

(iii) As the temperature increased, the energy exchange of the nanoparticle-base fluid contact increased

(i) The interface temperature was reduced between the heater and water block

(ii) The heat transfer enhanced by the use of the nanoparticles in the base fluid; the

Selvakumar and Water $\quad \mathrm{CuO} \quad 0.1,0.2 \quad$ Heat sink Suresh [19] Water $\quad \mathrm{CuO} \quad 0.1,0.2 \quad 55 \times 55 \times 75 \mathrm{~mm}$

Turbulent maximum heat transfer enhancement was approximately $29 \%$

(iii) The increase of the pressure drop was less than the increase in the convective heat transfer

(i) The nanoparticles concentration did not show much effect on heat transfer enhancement in turbulent regime

\begin{tabular}{|c|c|c|c|c|c|}
\hline $\begin{array}{l}\text { Fotukian and } \\
\text { Esfahany [8] }\end{array}$ & Water & $\mathrm{CuO}$ & $\begin{array}{c}0.039,0.078 \\
0.118,0.157 \\
0.236\end{array}$ & $\begin{array}{l}\text { Circular tube } \\
\text { L: } 1 \mathrm{~m} \text {; OD: } 32 \mathrm{~mm} \text {; } \\
\text { Thick: } 5 \mathrm{~mm}\end{array}$ & Turbulent \\
\hline
\end{tabular}

(ii) The ratio of convective heat transfer coefficient of nanofluid to that of pure water decreased with the increasing Reynolds number

(i) The suspended $\mathrm{CuO}$ nanoparticles increased the heat transfer, even for a low Saeedinia et al. [20]

Oil $\quad \mathrm{CuO} \quad 0.02,0.5,1,2$

Circular tube

Oil $\mathrm{CuO}$

L: $1200 \mathrm{~mm}$; OD:

$15.8 \mathrm{~mm}$; ID: $14 \mathrm{~mm}$

Laminar volume fraction

(ii) The maximum heat transfer enhancement of oil based nanofluid was approximately $12.7 \%$ at $2.0 \mathrm{vol} . \%$

(i) Remarkable heat transfer enhancement was observed as well as the pressure drop by the inclusion of the nanoscaled particles into the base fluid

$\begin{array}{lcccc} & & \text { Round copper tubes } \\ \text { Pooyan Razi et } & \text { Oil } & \mathrm{CuO} & \text { L: } 1200 \mathrm{~mm} \text {; OD: } & \text { Laminar } \\ \text { al. [21] } & & & 12.7 \mathrm{~mm} \text {; Thick: } & 0.6 \mathrm{~mm}\end{array}$

(ii) As the tube profile became more flattened, the heat transfer enhancement increased, and the same behaviour was valid for the pressure drop

(iii) The maximum heat transfer enhancement was $26.4 \%$ at $2 \%$ vol. for the flattened tube compared to the pure oil.

$L:$ length of the test tube, OD: outer diameter, ID: inner diameter, and Thick: thickness.

of the surfactants on thermal conductivity. The nanofluids in four different particle volume fractions $(0.5 \%, 1 \%, 2 \%$, and $4 \%$ ) have been sonicated about 20 hours by using Hielscher UP200S ultrasonic homogenizer. No sedimentation has been observed, and it has been seen that the nanofluids are stable up to 28 days under static conditions.

2.2. Experimental Set-Up. The experimental set-up used in this study is schematically shown in Figure 2, which consists of a heating unit, a cooling unit, a flow circulation unit, a control, and the measurement unit. The test section made from aluminum pipe has thermocouples, heater tapes, and pressure transmitters (Huba Control Inc.). The inner diameter of the aluminum test pipe with a length of $770 \mathrm{~mm}$ is $11.7 \mathrm{~mm}$ and the thickness is $1.5 \mathrm{~mm}$. The test pipe was heated with coiled heaters, which provided a constant heat flux boundary condition. The heater output power was $2000 \mathrm{~W}$ at $187 \mathrm{~V}$, and the measurement current was $10.7 \mathrm{~A}$. The electrical power input to the heater was controlled by a Variac transformer to obtain constant heat flux along the test tube. The power supplied to the heater was controlled and measured with a power analyzer (Hioki USA Inc.). The outside of the test pipe was insulated with a layer of glass wool and rock wool. The flow rates were measured with an 


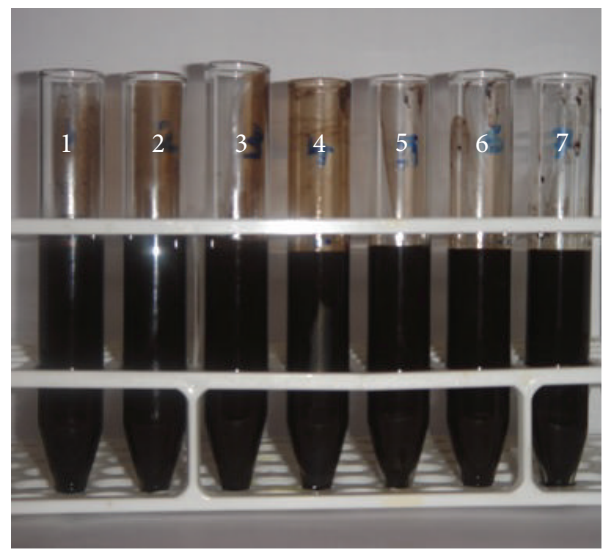

Figure 1: Nanofluid samples prepared by surfactants for 0.5 vol.\% at 10th day.

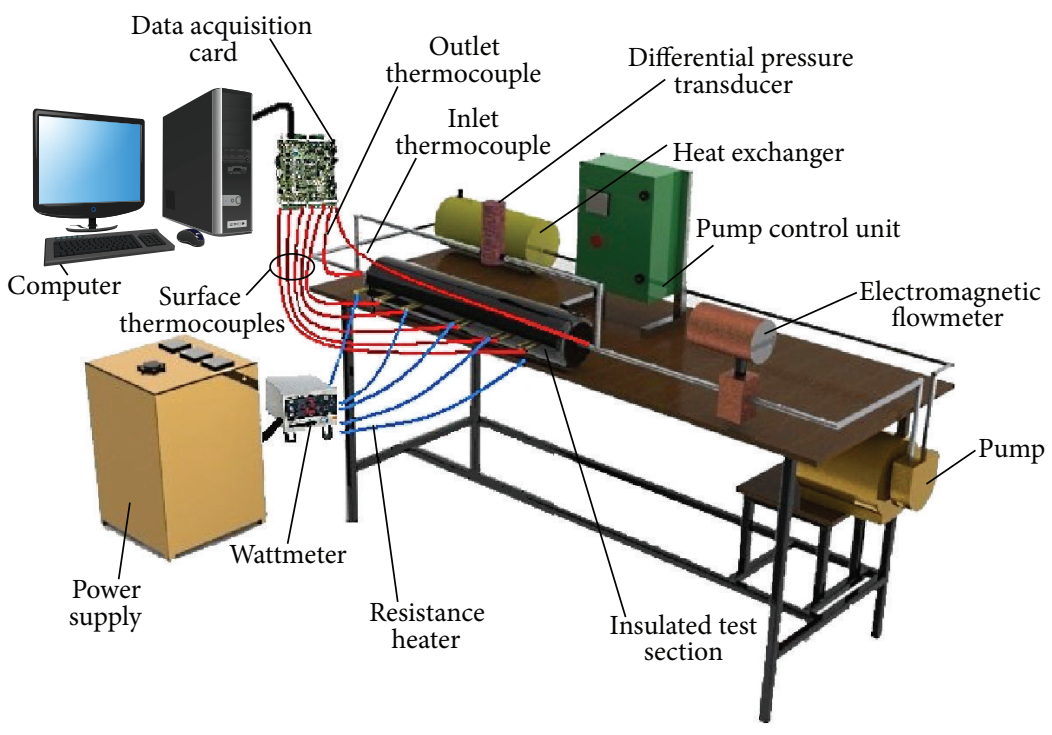

FIGURE 2: Experimental set-up.

electromagnetic flowmeter (Euromag International) and the flowmeter was validated before the use. A pump, a flowmeter, a tank, and a collecting tank are used in the flow circulation unit. For the data collection, a computer, a data acquisition card, a multiplexer, and a printer were used.

Two thermocouples were inserted into the flow at the inlet and outlet of the test section to measure bulk temperatures of nanofluids. The steady-state inlet and outlet bulk temperatures of the nanofluids and the surface temperature of the pipe at seven stations were measured by copper-constantan thermocouples with $0.25 \mathrm{~mm}$ inner diameter.

The copper-constantan thermocouples were calibrated in a thermostat (Polyscience) within $\pm 0.1^{\circ} \mathrm{C}$ deviation before using them in the experiments. The readings of the thermocouples were recorded using a computer via a data acquisition card (ADVANTEC, HG818 and 789D multiplexer), and the average of these readings was taken. The temperature of the pipe surface was taken as the average of the readings from the seven thermocouples. It is assumed that the steadystate conditions were reached when the variations on each temperature station were lower than $0.5^{\circ} \mathrm{C}$. Whenever the thermal equilibrium was reached, the measured data was recorded. The Reynolds number of the $\mathrm{CuO}$-water nanofluid ranging from 4.000 to 20.000 was based on the bulk mean properties and the pipe inner diameter.

2.3. Data Processing. The convective heat transfer rate $\dot{Q}_{\text {conv }}$ from electrically heated test section is calculated by using

$$
\dot{Q}_{\text {conv }}=\dot{Q}_{\text {elect }}-\dot{Q}_{\text {cond }}-\dot{Q}_{\text {rad }}
$$

where $\dot{Q}$ indicates the heat transfer rate in which subscripts conv, elect, cond, and rad denote convection, electrical, conduction, and radiation, respectively. The electrical heat input is calculated from the electrical potential and current supplied to the test tube.

In similar studies, investigators $[6,33-36]$ reported that total radiative heat loss from a similar test surface would be about 5 percent of the total electrical heat input. Using these findings, together with the fact that the test section was well 
insulated and readings of the thermocouple placed at the outer surface temperature of the heating section were nearly equal to ambient temperature, one could assume with some confidence that the last two terms of (1) may be ignored:

$$
\dot{Q}_{\text {conv }}=\dot{Q}_{\text {elect }}=\frac{V^{2}}{R}=V I \text {. }
$$

The heat transfer from the test section by convection can also be expressed as

$$
\dot{Q}_{\text {conv }}=h A\left[T_{s}-T_{m}\right] \text {. }
$$

The average heat transfer coefficient for the heated test section can be calculated by the combination of (1), (2), and (3):

$$
h=\frac{\dot{Q}_{\mathrm{conv}}}{A\left(T_{s}-T_{m}\right)} .
$$

Local convective heat transfer coefficient can be calculated by (5) because the local surface temperature $T_{s}(x)$ is known by measurement:

$$
\begin{aligned}
h_{x} & =\frac{\dot{Q}_{\text {conv }}}{A\left(T_{s}(x)-T_{m}(x)\right)}, \\
T_{m}(x) & =T_{\text {in }}+\frac{q^{\prime \prime} p}{\dot{m} C_{p}} x .
\end{aligned}
$$

In (6), $q^{\prime \prime}$ and $p$ are the heat flux and perimeter of the test tube, respectively. The local and average Nusselt numbers are calculated as follows:

$$
\begin{aligned}
\mathrm{Nu}_{x} & =\frac{h_{x} x}{k_{n, f}}, \\
\mathrm{Nu} & =\frac{h D}{k_{n, f}} .
\end{aligned}
$$

The Reynolds number and the friction factor are defined by using (8) and (9). Consider

$$
\begin{aligned}
\operatorname{Re} & =\frac{\rho_{n, f} U D}{\mu_{n, f}}, \\
f & =\frac{\Delta P}{(L / D)\left(\rho_{n, f}\left(U^{2} / 2\right)\right)}, \\
T_{m} & =\frac{\left(T_{\text {in }}+T_{\text {out }}\right)}{2} .
\end{aligned}
$$

The thermophysical properties of the water based $\mathrm{CuO}$ nanofluid used in all calculations were obtained using the bulk mean temperature given in (11).

2.4. Thermophysical Properties. The thermophysical properties of the water based $\mathrm{CuO}$ nanofluid were calculated below and presented in Table 2:

(i) The specific heat capacity $\left(C_{p_{n, f}}\right)$ of the nanofluid was calculated using [9]

$$
\left(\rho C_{p}\right)_{n, f}=(1-\phi) \cdot\left(\rho C_{p}\right)_{f}+\phi \cdot\left(\rho C_{p}\right)_{p} .
$$

TABLE 2: Thermophysical properties of the CuO-water nanofluid at $293 \mathrm{~K}$.

\begin{tabular}{lcccc}
\hline $\begin{array}{l}\text { Volume } \\
\text { fraction } \\
(\%)\end{array}$ & $\begin{array}{c}\text { Thermal } \\
\text { conductivity } \\
(\mathrm{W} / \mathrm{mK})\end{array}$ & $\begin{array}{c}\text { Specific } \\
\text { heat } \\
(\mathrm{J} / \mathrm{kgK})\end{array}$ & $\begin{array}{c}\text { Density } \\
\left(\mathrm{kg} / \mathrm{m}^{3}\right)\end{array}$ & $\begin{array}{c}\text { Viscosity } \\
\left(\mathrm{N} \cdot \mathrm{m} / \mathrm{s}^{2}\right) * 10^{-3}\end{array}$ \\
\hline $\begin{array}{l}\text { (pure } \\
\text { water) }\end{array}$ & 0.602 & 4182.0 & 998.54 & 1.006 \\
0.5 & 0.611 & 4069.6 & 1025.1 & 1.471 \\
1 & 0.620 & 3962.9 & 1051.7 & 1.477 \\
2 & 0.638 & 3764.9 & 1104.9 & 1.48 \\
4 & 0.676 & 3421.0 & 1211.3 & 1.482 \\
\hline
\end{tabular}

TABLE 3: Uncertainty analysis results.

\begin{tabular}{lccc}
\hline Parameters & $\mathrm{Re}$ & $f$ & $\mathrm{Nu}$ \\
\hline Uncertainty $\%$ & 8.54 & 8.32 & 7.28 \\
\hline
\end{tabular}

(ii) The viscosity $\left(\mu_{n, f}\right)$ of the nanofluid was measured using a DV-I Prime viscometer with time function (Brookfield, Inc.) [25].

(iii) The effective thermal conductivity $\left(k_{n, f}\right)$ of the nanofluid was measured using a KD2 Pro thermal property meter (Decagon Devices, Inc.). This device using the transient hot wire method works by evaluating the time and temperature response of the sudden electric signals [25].

(iv) The density $\left(\rho_{n, f}\right)$ of the nanofluid was obtained by measuring the mass of a known volume of the nanofluid [25].

2.5. Experimental Uncertainties. Uncertainty analysis with respect to the variables was made by using Kline and McClintock equation [37]. Uncertainty analysis with respect to the Reynolds number, the friction factor, and the Nusselt number was made and presented in Table 3.

\section{Results and Discussion}

The results of pure water obtained from the experimental setup were compared with the well-known correlations of the friction factor and the Nusselt number in order to validate the set-up before starting the experiments. For the verification of the friction factor of the pure water, the correlations proposed by Blasius in (13) and Pethukov [38] in (14) were used. Likewise, the correlations of Dittus-Boelter in (15) and Pethukov in (16) were used for the comparison. The variations of the friction factor and the Nusselt number versus the Reynolds number are plotted in Figures 3 and 4, respectively. At lower flow velocities, the difference between the results of the present work and the correlations for the friction factor is approximately $20 \%$ due to nonsensitive readings at lower velocities. With increasing flow velocity, the difference gets lower and lower. The Nusselt number values of the present work are in good agreement with the correlations of Pethukov 


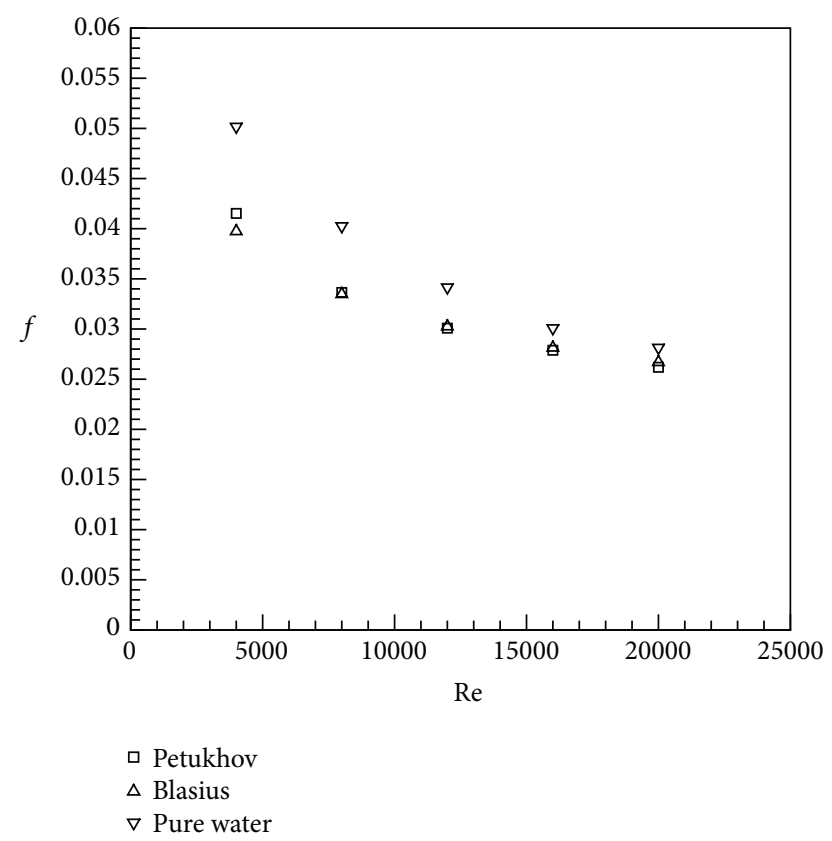

FIGURE 3: Comparison of the friction factor of the pure water with the correlations of Blasius and Petukhov.

and Dittus-Boelter. The particle volume concentrations are selected to be in a wide range of $0.5 \%, 1 \%, 2 \%$, and $4 \%$ in order to determine critical value after which the heat transfer deteriorates. Consider

$$
\begin{aligned}
f & =0.316 \operatorname{Re}_{D}{ }^{-0.25} \quad \operatorname{Re}_{D} \leq 20.000, \\
f & =\left(0.790 \ln \operatorname{Re}_{D}-1.64\right)^{-2} \\
\mathrm{Nu} & =0.023 \cdot \operatorname{Re}^{0.8} \cdot \operatorname{Pr}^{0.4}, \\
\mathrm{Nu} & =\frac{(f / 8) \operatorname{Re} \operatorname{Pr}}{1.07+12.7(f / 8)^{0.5}\left(\operatorname{Pr}_{D}{ }^{0.67}-1\right)} .
\end{aligned}
$$

In Figure 5, the Nusselt number variations of the water based $\mathrm{CuO}$ nanofluid are plotted versus the Reynolds number for both pure water and different particle volume fractions. As seen from the figure, the Nusselt number increases with increasing Reynolds number for all particle volume concentrations and pure water. The presence of the nanoscaled particles in the base fluid enhances heat transfer much more than pure water up to $1 \%$ particle volume fraction. At Re $=4.000$, the Nusselt number values of the nanofluids and the pure water are close. At the values of the Reynolds number higher than 10.000 , the Nusselt number becomes closer to that of the pure water due to an increase in the particle concentration, and the $\mathrm{CuO}$-water nanofluid has better performance than pure water in terms of heat transfer.

It is also seen from Figure 5 that the heat transfer rate increases by the increase of the particle volume fraction up to $1.0 \%$. At higher volume fractions than $1.0 \%$, the heat

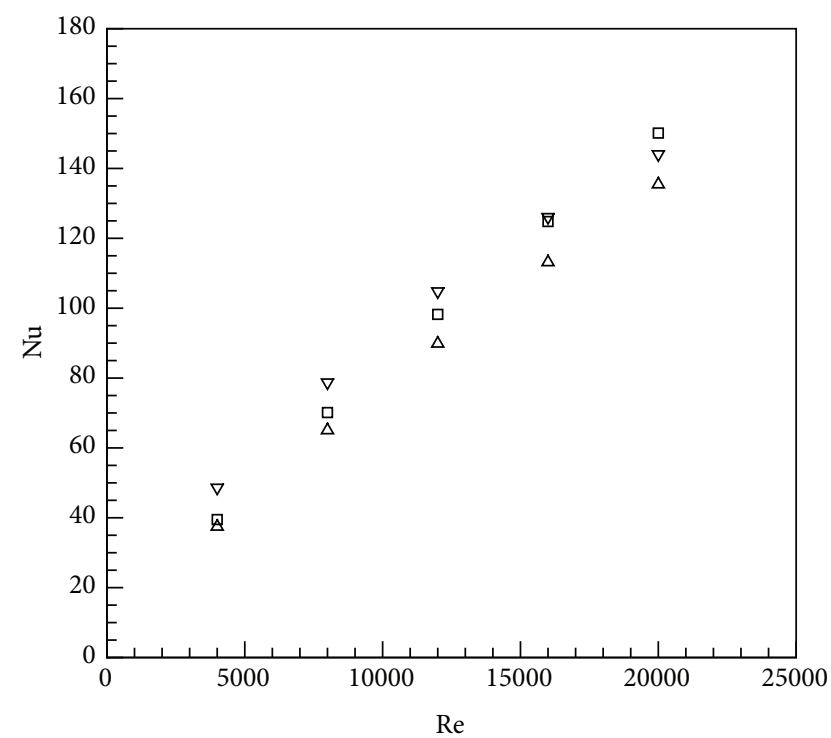

$$
\begin{aligned}
& \square \text { Petukhov } \\
& \Delta \text { Dittus-Boelter } \\
& \nabla \text { Pure water }
\end{aligned}
$$

FIGURE 4: Comparison of the Nusselt number of the pure water with the correlations of Dittus-Boelter and Petukhov.

transfer decreases unexpectedly. Adding nanosized metallic particles into the base fluid increases not only the thermal conductivity but also the viscosity of the fluid. An increase in the thermal conductivity enhances heat transfer as expected. However, after a critical value of particle volume fraction, the $\mathrm{CuO}$ nanofluid starts to convert a state of slurry. Until the flow reaches thermally the steady-state conditions, the inner surface of the bottom of the test tube is coated with the $\mathrm{CuO}$ nanoparticles due to agglomeration at higher concentrations and thus an extra thermal resistance occurs. In brief, the increase of the viscosity intensifies viscous sublayer in which heat transfer occurs due to molecular motion and causes the performance of the heat transfer to decrease.

For the particle volume concentrations higher than $1 \mathrm{vol} . \%$, the effect of the viscosity is dominant over that of the increase of the thermal conductivity. The variations of the friction factor are illustrated in Figure 6 for both pure water and different particle volume fractions. The friction factor for all volume concentrations decreases with increasing Reynolds number, and the lowest friction factor is obtained for pure water. After $\operatorname{Re}=10.000$, the friction factors of the nanofluids and the pure water are so close to each other.

Figure 7 shows the changes of the local Nusselt number along the $x$-distance for different volume fractions and different Reynolds numbers. In Figures 7(a), 7(b), 7(c), and $7(d)$, the local Nusselt number increases with increasing Reynolds number. At the channel inlet $(x / D<10)$, the local Nusselt number is considerably high, which means the coefficient of the convection heat transfer is high in this region. After $x / D=10$, the local Nusselt number does not change so much and is nearly constant in a general trend. The local Nusselt number increases with an increase in the 


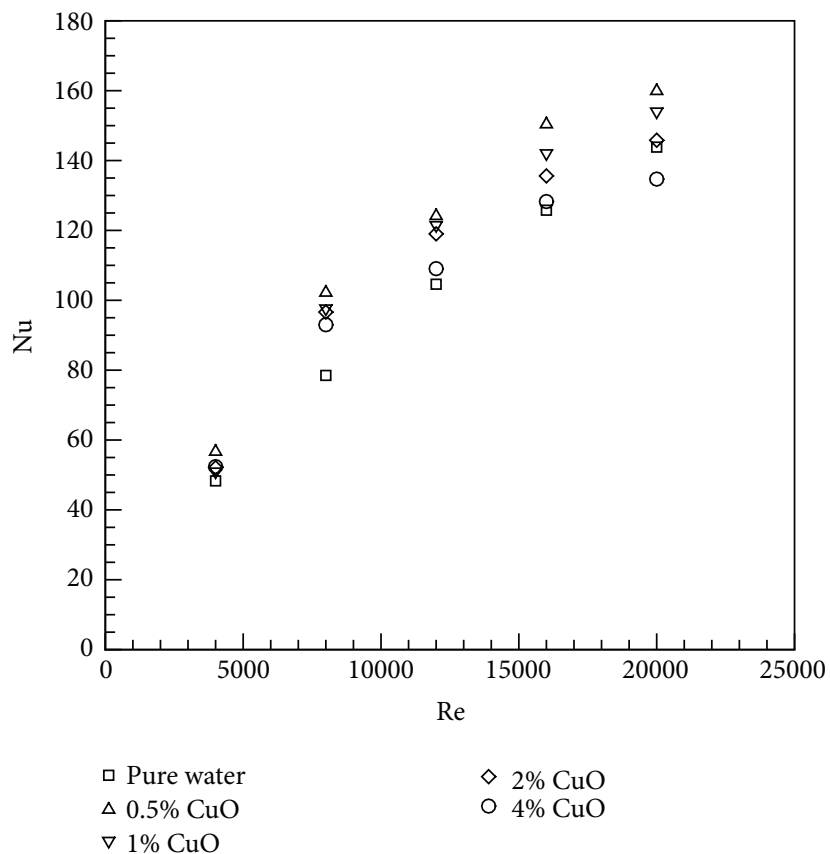

FIGURE 5: The variations of the Nusselt number versus the Reynolds number at various particle volume concentrations.

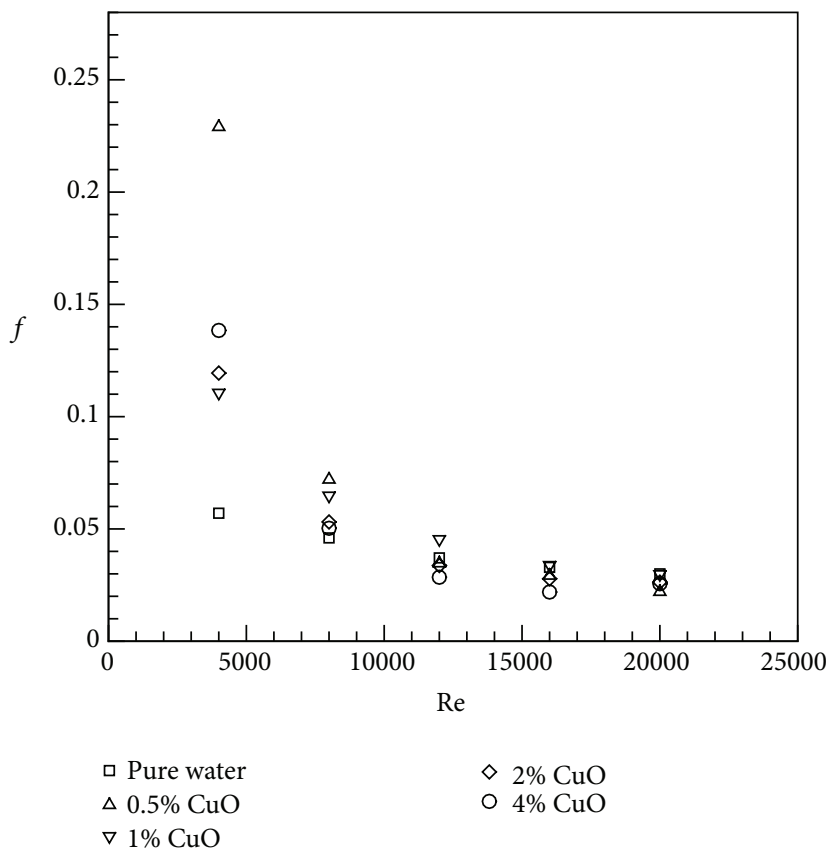

FIGURE 6: The variations of the friction factor versus the Reynolds number at various particle volume concentrations.

particle volume fraction up to $1 \%$ vol. At higher values of $1 \%$ vol., the local Nusselt number decreases with increasing particle volume fraction.

The overall heat transfer enhancement of the $\mathrm{CuO}$ water nanofluid for all particle volume concentrations is also calculated to evaluate the total effect of the heat transfer and the friction factor. It is well known that there is a net gain of energy for the cases where overall heat transfer enhancement rate is greater than one. Therefore, this case is useful with respect to the heat transfer and the friction factor. As seen in Figure 8, no heat transfer enhancement is observed at $\mathrm{Re}=$ 4.000 . For the case of $4 \%$ vol., the heat transfer enhancement is obtained for the range of the Reynolds number of 8.00016.000. The highest overall heat transfer enhancement is 

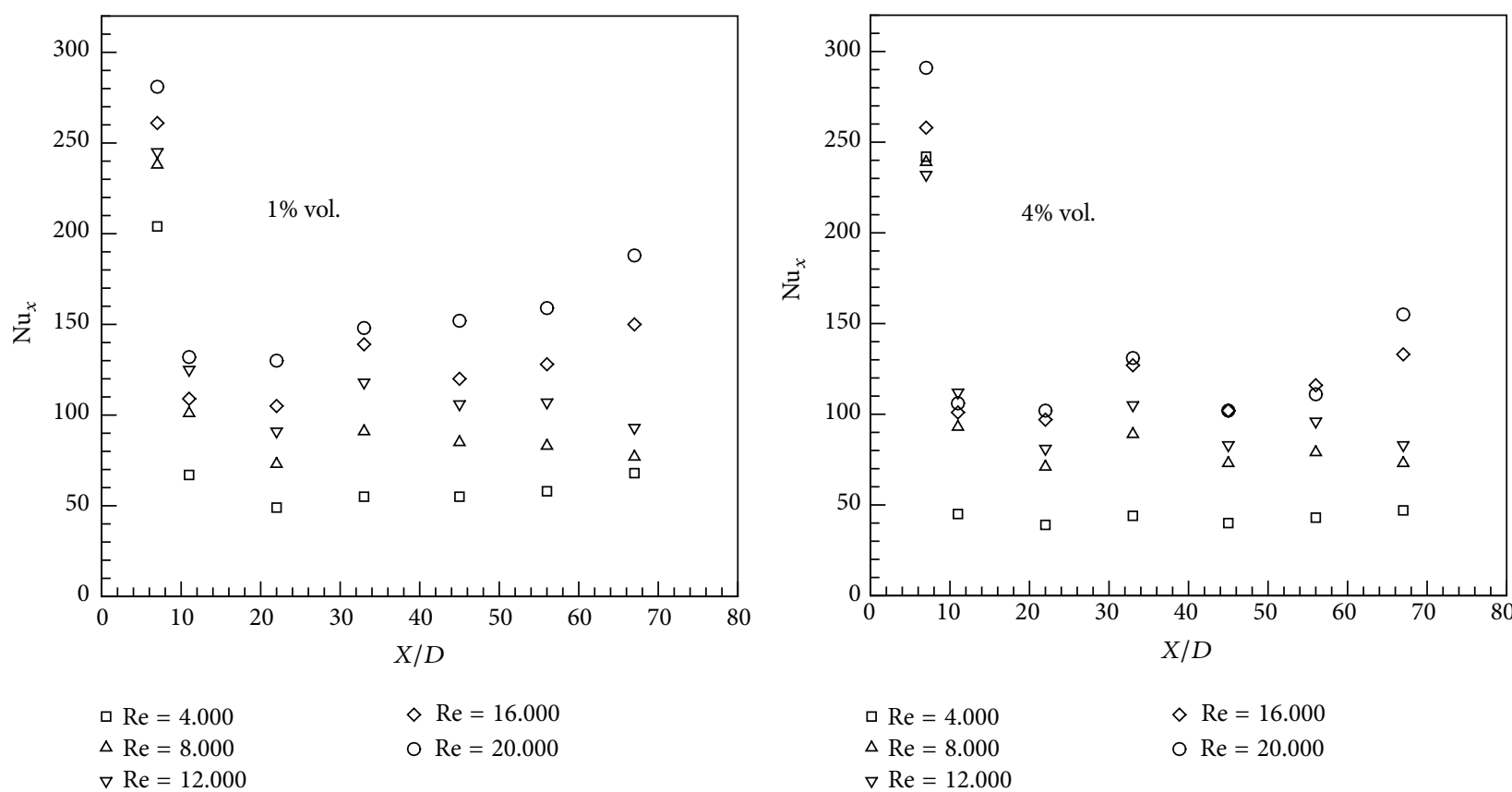

(a)

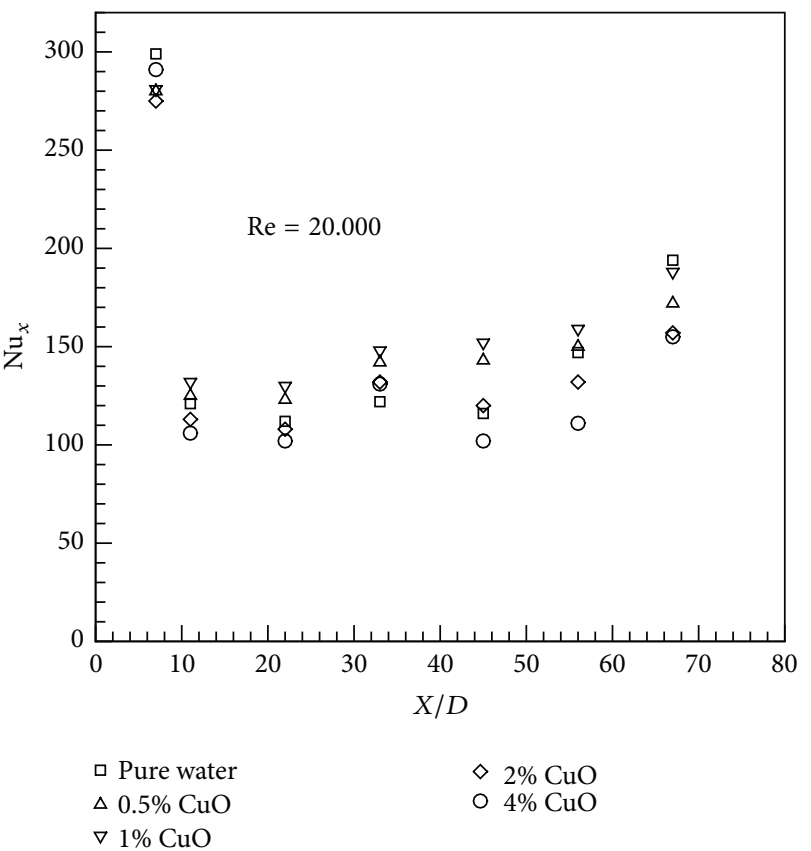

(c)

(d)

Figure 7: The variations of the local Nusselt number versus $x / D$ for (a) $1 \%$ vol., (b) $4 \%$ vol., (c) $\operatorname{Re}=4.000$, and (d) $\operatorname{Re}=20.000$.

achieved for the case of $\operatorname{Re}=16.000$ and $\phi=0.005$, and the lowest one is found to be at $\operatorname{Re}=20.000$ and $\phi=0.02$.

\section{Conclusions}

This paper presented an experimental study of the turbulent flow convective heat transfer and the pressure drop characteristics and heat transfer enhancement capability of the $\mathrm{CuO}$-water nanofluid inside a circular tube. The $\mathrm{CuO}$-water nanofluids with the loadings of $0.5 \%, 1 \%, 2 \%$, and $4 \%$ were used. The concluding remarks are presented below:

(i) The presence of nanoscaled particles in the base fluid enhanced heat transfer much more than pure water up to a limited value of particle volume fraction $(0.5 \%)$.

(ii) At the values of the Reynolds number higher than 10.000, the Nusselt number got closer to that of the 


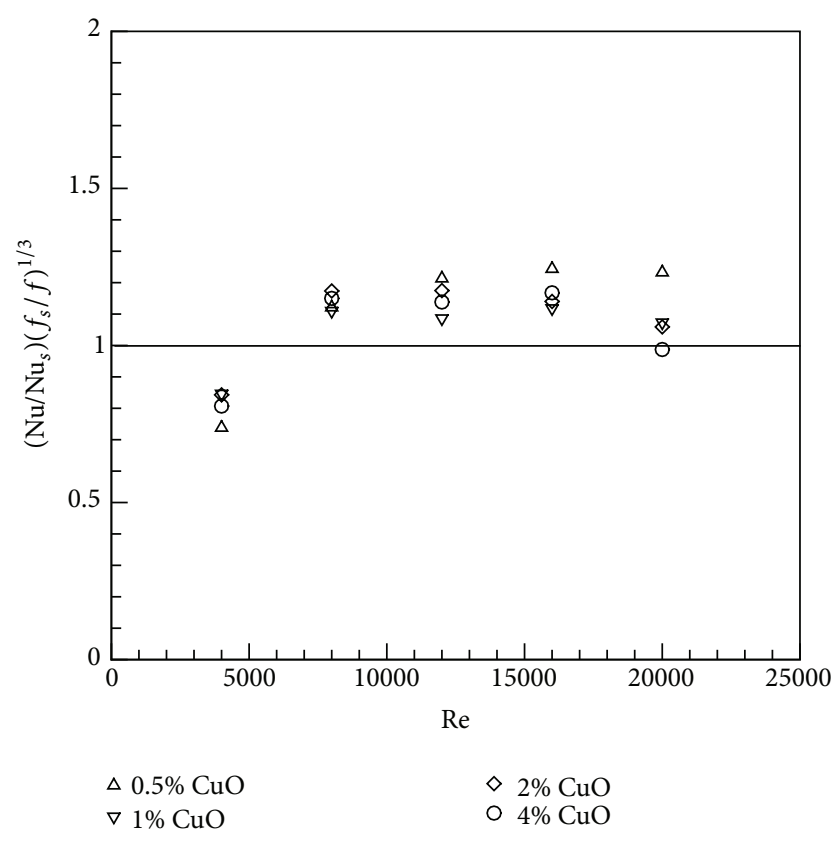

Figure 8: Heat transfer enhancement versus the Reynolds number at various particle volume concentrations.

pure water by the increase of the particle concentration, and the $\mathrm{CuO}$-water nanofluid exhibited better performance in terms of heat transfer.

(iii) The presence of the nanosized $\mathrm{CuO}$ particles in the base fluid (water) higher than $0.5 \%$ vol. was not appropriate in terms of heat transfer.

(iv) The local Nusselt number increases with the increase of the particle volume fraction up to $1 \%$ vol. At higher values than $1 \%$ vol., the local Nusselt number decreased with increasing particle volume fraction.

(v) No heat transfer enhancement was observed at $\mathrm{Re}=$ 4.000. The highest heat transfer enhancement was achieved in the case of $\operatorname{Re}=16.000$ and $\phi=0.005$; the lowest one was obtained at $\operatorname{Re}=20.000$ and $\phi=0.02$.

\section{Nomenclature}

A: Heat transfer area $\left(\mathrm{m}^{2}\right)$

$C_{p}$ : Specific heat $(\mathrm{J} / \mathrm{kgK})$

$D$ : Inner diameter of the test tube (m)

$f$ : Friction factor (dimensionless)

$h$ : Heat transfer coefficient $\left(\mathrm{W} / \mathrm{m}^{2} \mathrm{~K}\right)$

I: Current (ampere)

$L: \quad$ Length of the test tube $(\mathrm{m})$

$k$ : Thermal conductivity $(\mathrm{W} / \mathrm{mK})$

$\mathrm{Nu}$ : Nusselt number (dimensionless)

Pr: Prandtl number (dimensionless)

Q: Heat transfer $(\mathrm{W})$

$R: \quad$ Resistance $(\mathrm{Ohm})$

Re: Reynolds number (dimensionless)

T: $\quad$ Steady-state temperature $(\mathrm{K})$

$U$ : Velocity of the fluid in $x$-direction $(\mathrm{m} / \mathrm{s})$
$V:$ Voltage (Volt)

$x$ : Axial distance from the tube entrance (m)

$\Delta P$ : Pressure difference $(\mathrm{Pa})$

$\dot{m}$ : Mass flow rate $(\mathrm{kg} / \mathrm{s})$.

Subscripts

in: Inlet

out: Outlet

$m$ : Bulk mean

$n, f:$ Nanofluid

s: $\quad$ Surface.

Greek Letters

$\mu$ : Fluid dynamic viscosity (Pa-s)

$\rho$ : Fluid density $\left(\mathrm{kg} / \mathrm{m}^{3}\right)$

p: Particle volume concentration.

\section{Conflict of Interests}

The authors declare that there is no conflict of interests regarding the publication of this paper.

\section{Acknowledgments}

This study was supported by The Turkish Scientific and Technological Research Council of Turkey (TÜBITAK Project no. 105M292) and Ataturk University Research Project Foundation (Project no. BAP-2007/50). The authors wish to thank TUBITAK and Ataturk University.

\section{References}

[1] W. Duangthongsuk and S. Wongwises, "Comparison of the effects of measured and computed thermophysical properties of nanofluids on heat transfer performance," Experimental Thermal and Fluid Science, vol. 34, no. 5, pp. 616-624, 2010.

[2] J.-H. Lee, K. S. Hwang, S. P. Jang et al., "Effective viscosities and thermal conductivities of aqueous nanofluids containing low volume concentrations of $\mathrm{Al}_{2} \mathrm{O}_{3}$ nanoparticles," International Journal of Heat and Mass Transfer, vol. 51, no. 11-12, pp. 26512656, 2008.

[3] W. Daungthongsuk and S. Wongwises, "A critical review of convective heat transfer of nanofluids," Renewable and Sustainable Energy Reviews, vol. 11, no. 5, pp. 797-817, 2007.

[4] G. Gedik, Determination of heat transfer and pressure drop of nanofluids [Ph.D. thesis], Ataturk University, Erzurum, Turkey, 2009.

[5] X.-Q. Wang and A. S. Mujumdar, "Heat transfer characteristics of nanofluids: a review," International Journal of Thermal Sciences, vol. 46, no. 1, pp. 1-19, 2007.

[6] W. Duangthongsuk and S. Wongwises, "An experimental study on the heat transfer performance and pressure drop of $\mathrm{TiO}_{2}$ water nanofluids flowing under a turbulent flow regime," International Journal of Heat and Mass Transfer, vol. 53, no. 1-3, pp. 334-344, 2010

[7] M. N. Pantzali, A. A. Mouza, and S. V. Paras, "Investigating the efficacy of nanofluids as coolants in plate heat exchangers (PHE)," Chemical Engineering Science, vol. 64, no. 14, pp. 3290 3300, 2009 . 
[8] S. M. Fotukian and M. N. Esfahany, "Experimental study of turbulent convective heat transfer and pressure drop of dilute $\mathrm{CuO}$ /water nanofluid inside a circular tube," International Communications in Heat and Mass Transfer, vol. 37, no. 2, pp. 214-219, 2010.

[9] I. Gherasim, G. Roy, C. T. Nguyen, and D. Vo-Ngoc, "Experimental investigation of nanofluids in confined laminar radial flows," International Journal of Thermal Sciences, vol. 48, no. 8, pp. 1486-1493, 2009.

[10] L. S. Sundar and K. V. Sharma, "Turbulent heat transfer and friction factor of $\mathrm{Al}_{2} \mathrm{O}_{3}$ Nanofluid in circular tube with twisted tape inserts," International Journal of Heat and Mass Transfer, vol. 53, no. 7-8, pp. 1409-1416, 2010.

[11] Y. Xuan and Q. Li, "Investigation on convective heat transfer and flow features of nanofluids," Journal of Heat Transfer, vol. 125, no. 1, pp. 151-155, 2003.

[12] R. Chein and G. Huang, "Analysis of micro-channel heat sink performance using nanofluids," Applied Thermal Engineering, vol. 25, no. 17-18, pp. 3104-3114, 2005.

[13] H. B. Ma, C. Wilson, B. Borgmeyer et al., "Effect of nanofluid on the heat transport capability in an oscillating heat pipe," Applied Physics Letters, vol. 88, no. 14, Article ID 143116, 2006.

[14] C. Y. Tsai, H. T. Chien, P. P. Ding, B. Chan, T. Y. Luh, and P. H. Chen, "Effect of structural character of gold nanoparticles in nanofluid on heat pipe thermal performance," Materials Letters, vol. 58, no. 9, pp. 1461-1465, 2004.

[15] H. T. Chien, C. I. Tsai, P. H. Chen, and P. Y. Chen, "Improvement on thermal performance of a disk-shaped miniature heat pipe with nanofluid," in Proceedings of the 5th International Conference on Electronic Packaging Technology (ICEPT '03), IEEE Cat. No. 03EX750, pp. 389-391, Shanghai, China, October 2003.

[16] S. P. Jang and S. U. S. Choi, "Cooling performance of a micro-channel heat sink with nanofluids," Applied Thermal Engineering, vol. 26, no. 17-18, pp. 2457-2463, 2006.

[17] S. Lee and S. U. S. Choi, "Application of metallic nanoparticle suspensions in advanced cooling systems," in Proceedings of the International Mechanical Engineering Congress and Exhibition, December 1996.

[18] L. G. Asirvatham, N. Vishal, S. K. Gangatharan, and D. M. Lal, "Experimental study on forced convective heat transfer with low volume fraction of $\mathrm{CuO}$ /Water nanofluid," Energies, vol. 2, no. 1, pp. 97-119, 2009.

[19] P. Selvakumar and S. Suresh, "Convective performance of $\mathrm{CuO} /$ water nanofluid in an electronic heat sink," Experimental Thermal and Fluid Science, vol. 40, pp. 57-63, 2012.

[20] M. Saeedinia, M. A. Akhavan-Behabadi, and P. Razi, "Thermal and rheological characteristics of $\mathrm{CuO}$-Base oil nanofluid flow inside a circular tube," International Communications in Heat and Mass Transfer, vol. 39, no. 1, pp. 152-159, 2012.

[21] P. Pooyan Razi, M. A. Akhavan-Behabadi, and M. Saeedinia, "Pressure drop and thermal characteristics of CuO-base oil nanofluid laminar flow in flattened tubes under constant heat flux," International Communications in Heat and Mass Transfer, vol. 38, no. 7, pp. 964-971, 2011.

[22] S. M. Hashemi and M. A. Akhavan-Behabadi, "An empirical study on heat transfer and pressure drop characteristics of $\mathrm{CuO}$-base oil nanofluid flow in a horizontal helically coiled tube under constant heat flux," International Communications in Heat and Mass Transfer, vol. 39, no. 1, pp. 144-151, 2012.

[23] E. F. Dilek, Determination of heat transfer and pressure drop of nanofluids [Ph.D. thesis], Ataturk University, Erzurum, Turkey, 2008.
[24] Y. Li, J. Zhou, S. Tung, E. Schneider, and S. Xi, "A review on development of nanofluid preparation and characterization," Powder Technology, vol. 196, no. 2, pp. 89-101, 2009.

[25] B. Sahin, G. G. Gültekin, E. Manay, and S. Karagoz, "Experimental investigation of heat transfer and pressure drop characteristics of $\mathrm{Al}_{2} \mathrm{O}_{3}$-water nanofluid," Experimental Thermal and Fluid Science, vol. 50, pp. 21-28, 2013.

[26] X. F. Li, D. S. Zhu, X. J. Wang, N. Wang, J. W. Gao, and H. $\mathrm{Li}$, "Thermal conductivity enhancement dependent $\mathrm{pH}$ and chemical surfactant for $\mathrm{Cu}-\mathrm{H}_{2} \mathrm{O}$ nanofluids," Thermochimica Acta, vol. 469, no. 1-2, pp. 98-103, 2008.

[27] L. Yang, K. Du, and X.-S. Zhang, "Influence factors on thermal conductivity of ammonia-water nanofluids," Journal of Central South University, vol. 19, no. 6, pp. 1622-1628, 2012.

[28] H. Peng, G. Ding, and H. Hu, "Effect of surfactant additives on nucleate pool boiling heat transfer of refrigerant-based nanofluid," Experimental Thermal and Fluid Science, vol. 35, no. 6, pp. 960-970, 2011.

[29] W. Yu, H. Xie, L. Chen, and Y. Li, "Investigation on the thermal transport properties of ethylene glycol-based nanofluids containing copper nanoparticles," Powder Technology, vol. 197, no. 3, pp. 218-221, 2010.

[30] S. Iyahraja and J. S. Rajadurai, "Study of thermal conductivity enhancement of aqueous suspensions containing silver nanoparticles," AIP Advances, vol. 5, no. 5, Article ID 057103, 2015.

[31] R. Parashar, M. Wan, R. R. Yadav, A. C. Pandey, and V. Parashar, "Surfactant free synthesis of metal oxide (Co and $\mathrm{Ni}$ ) nanoparticles and applications to heat propagation in nanofluids," Materials Letters, vol. 132, pp. 440-443, 2014.

[32] G. Xia, H. Jiang, R. Liu, and Y. Zhai, "Effects of surfactant on the stability and thermal conductivity of $\mathrm{Al}_{2} \mathrm{O}_{3} /$ de-ionized water nanofluids," International Journal of Thermal Sciences, vol. 84, pp. 118-124, 2014.

[33] D. Wen and Y. Ding, "Experimental investigation into convective heat transfer of nanofluids at the entrance region under laminar flow conditions," International Journal of Heat and Mass Transfer, vol. 47, no. 24, pp. 5181-5188, 2004.

[34] Y. Ding, H. Alias, D. Wen, and R. A. Williams, "Heat transfer of aqueous suspensions of carbon nanotubes (CNT nanofluids)," International Journal of Heat and Mass Transfer, vol. 49, no. 1-2, pp. 240-250, 2006.

[35] M. Chandrasekar, S. Suresh, and A. C. Bose, "Experimental studies on heat transfer and friction factor characteristics of $\mathrm{Al}_{2} \mathrm{O}_{3}$ /water nanofluid in a circular pipe under laminar flow with wire coil inserts," Experimental Thermal and Fluid Science, vol. 34, no. 2, pp. 122-130, 2010.

[36] S.-S. Hsieh, M.-H. Liu, and F.-Y. Wu, "Developing turbulent mixed convection in a horizontal circular tube with strip-type inserts," International Journal of Heat and Mass Transfer, vol. 41, no. 8-9, pp. 1049-1063, 1998.

[37] S. J. Kline and F. A. McClintock, "Describing uncertainties in single-sample experiments," Mechanical Engineering, vol. 75, no. 1, pp. 3-8, 1953.

[38] B. S. Pethukov, "Heat transfer in turbulent pipe flow with variable physical properties," in Advances in Heat Transfer, J. P. Harnett, Ed., vol. 6, pp. 504-564, Academic Press, New York, NY, USA, 1970. 

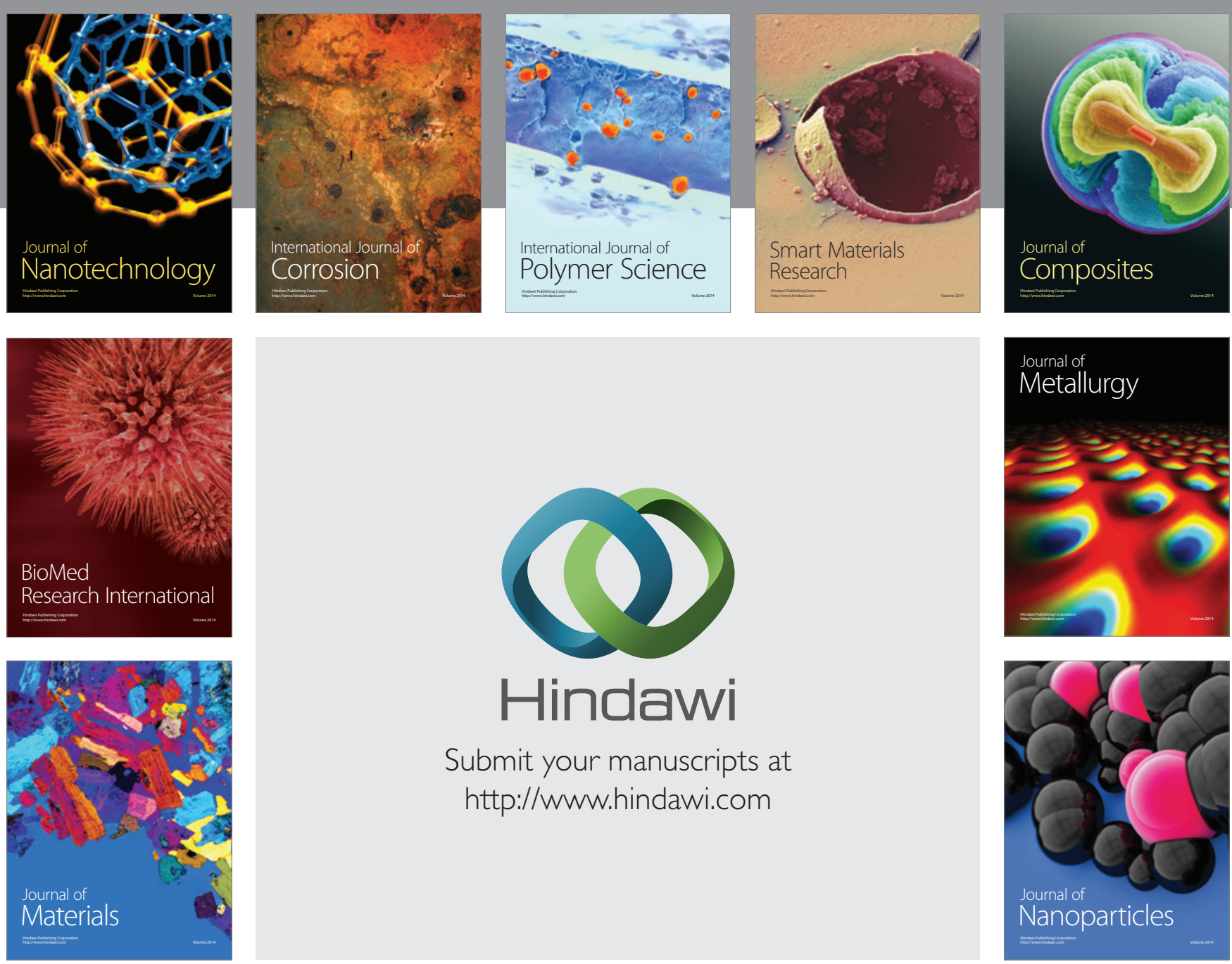

Submit your manuscripts at http://www.hindawi.com
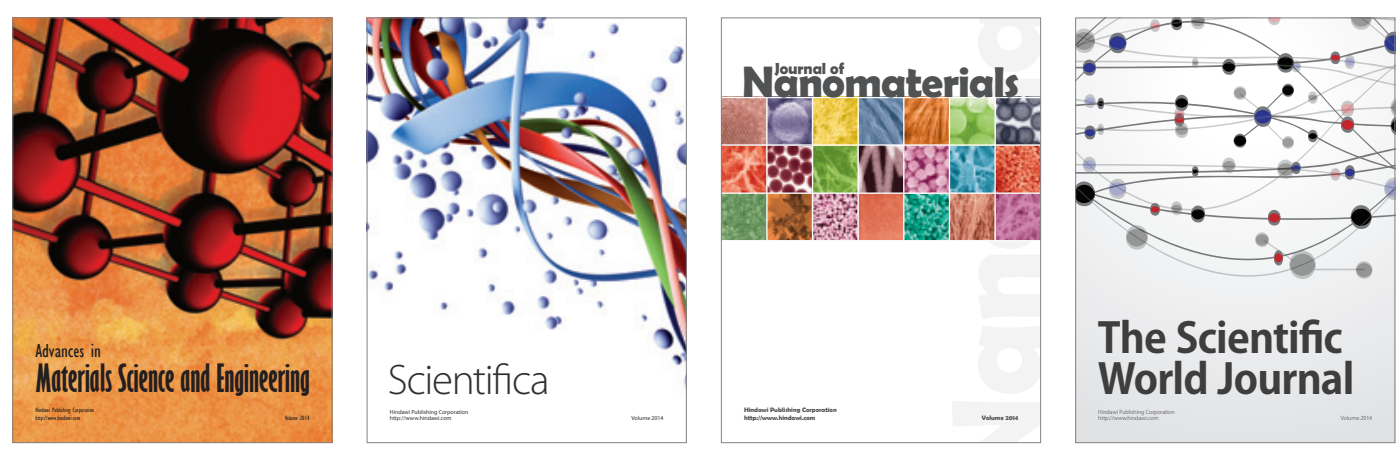

\section{The Scientific World Journal}
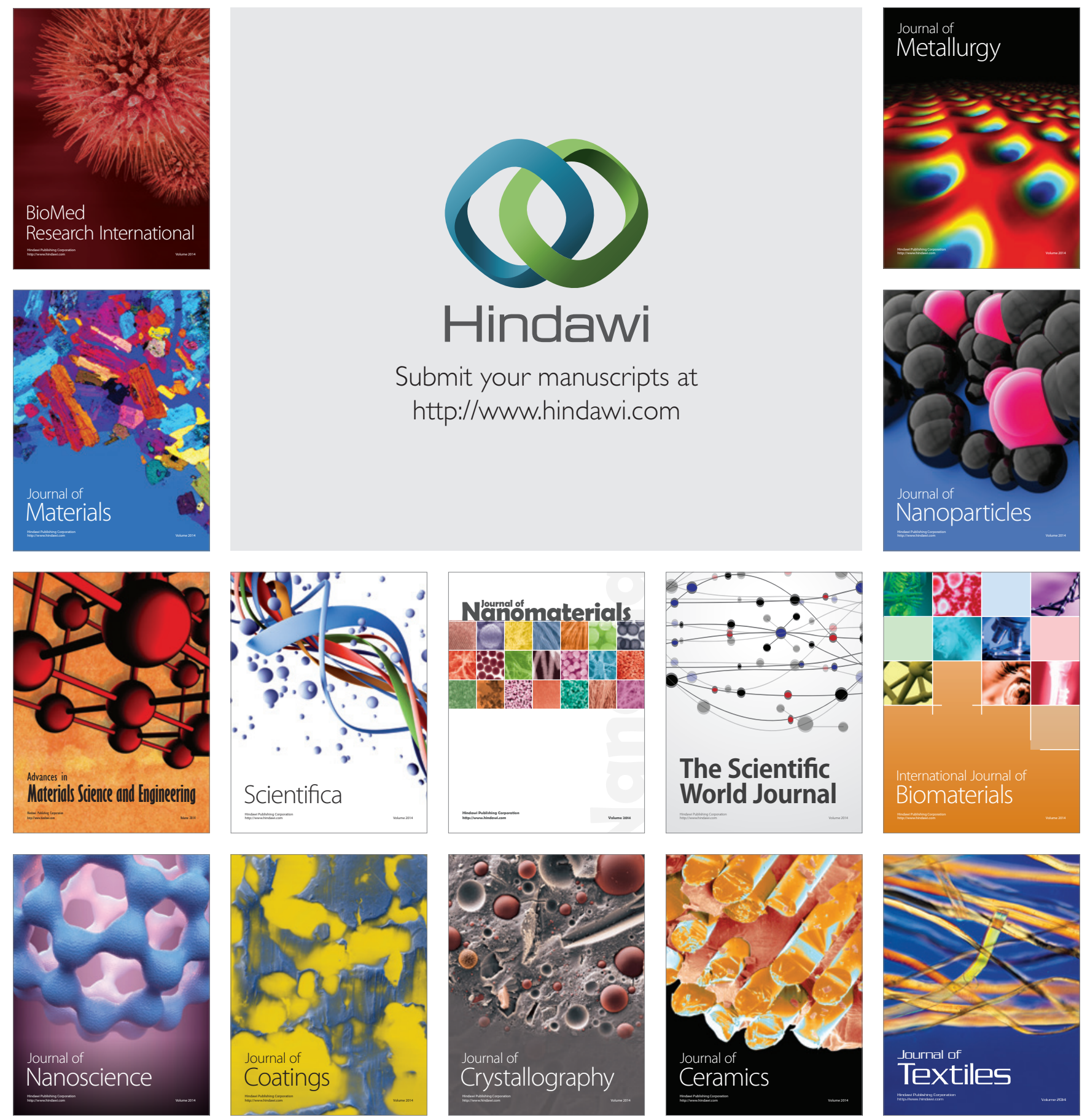